\title{
The scourge of knife crime: trends in knife-related assault managed at a major centre in South Africa
}

\author{
H Uchino, ${ }^{(1)}$ VY Kong, ${ }^{2,3}$ (D) A Pantelides, ${ }^{3}$ (D) J Anderson, ${ }^{3}$ (D) H O'Neill, ${ }^{3}$ (D) JL Bruce, ${ }^{3}$ (D) GL Laing, ${ }^{3}$ DL Clarke \\ ${ }^{1}$ Department of Surgery, Department of Critical Care Medicine, Kurashiki Central Hospital, Okayama, Japan \\ ${ }^{2}$ Department of Surgery, University of the Witwatersrand, Johannesburg, South Africa \\ ${ }^{3}$ Department of Surgery, University of KwaZulu-Natal, Durban, South Africa
}

Corresponding author, email: victorywkong@yahoo.com

Background: Knife wounds are common and represent a major burden to the South African healthcare system. This study reviews trends in spectrum, management and outcome of these injuries at a single trauma centre in KwaZulu-Natal (KZN).

Methods: The regional hybrid electronic registry (HEMR) was reviewed for the period January 2013 - December 2018 , and all patients who suffered a knife-related assault were identified and reviewed.

Results: During the period under review, a total of 2117 patients suffered a knife-related assault. Regions injured were as follows: head 445, neck 572, face 258, chest 939, abdomen 649, pelvic/urogenital 49, upper limb 418, and lower limb 105. The median ISS was 9 (4-10). Imaging comprised 1242 chest X-rays, 315 abdominal X-rays, 162 abdominal ultrasounds/ FAST, and 929 CT scans of which 634 were CT angiograms. A total of 783 (37\%) patients required an operation. The rate of laparotomy was $447 / 649(69 \%)$ and of thoracotomy/sternotomy/thoracoscopy $95 / 939(10 \%)$. The rate of vascular exploration for upper and lower limb vascular injury was 101/523 (19\%). Mortality was 49/2117 (2.3\%).

Conclusion: Although our clinical outcomes over this period appear to be consistent, suggesting a familiarity with managing knife-related trauma, the persistently high rate of knife-related injury suggests that we have failed to develop a preventative strategy to try and reduce this scourge.

Keywords: knife crimes, assault, major cities, South Africa

\section{Introduction}

South Africa continues to experience an excessive burden of inter-personal violence despite a quarter of a century of democracy. The situation in South Africa appears to be intractable and knife crime is endemic throughout the country. ${ }^{1}$ Other parts of the world are now also experiencing a worrying increase in inter-personal violence. Major cities such as London are frequently in the news as a result of knife crime. The reasons for this increase remain opaque, but mass immigration, and economic uncertainty in the wake of the financial turmoil of the last decade may all have contributed to this so-called 'scourge of knife crime'. ${ }^{2}$ If this situation is not contained, there is a very real danger that knife crime in countries such as the United Kingdom may become an intractable problem just as in South Africa. ${ }^{3,4}$ The response to knife crime requires a multifactorial approach and there are many advocates of treating knife crime in the same way as a public health infectious disease emergency is managed. ${ }^{5}$ Prevention will involve legislation, law enforcement and education. ${ }^{6,7,8}$ All preventative strategies must be based on accurate data and the disease needs to be tracked and monitored in the same way as infectious diseases are tracked by the World Health Organization (WHO) and Communicable Disease Control (CDC). ${ }^{9}$ Historically, the lack of a robust record system has hampered attempts in
South Africa to track this disease. ${ }^{10}$ Previously all attempts to provide some type of overview or perspective on the burden of trauma within most provinces were by necessity static 'snapshots in time' of an ongoing epidemic. At our trauma centre, an electronic regional trauma registry was established in 2012, called the Hybrid electronic medical registry (HEMR). This system has run for six years and has captured all surgical admissions over that period. The longevity of the system is now allowing us to develop a nascent ability to track temporal trends across the city. ${ }^{11}$ This paper is an attempt to provide a six-year overview of kniferelated trauma managed at our centre. It is hoped that this analysis will provide an overview of the disease in our city and allow us to identify possible interventions. A secondary aim is to assess the quality of the data captured by the HEMR by interrogating its consistency over time.

\section{Materials and methods}

\section{Clinical setting}

The Pietermaritzburg Metropolitan Trauma Service (PMTS), a division within the Department of Surgery at Grey's Hospital, is based in the city of Pietermaritzburg, South Africa. It provides definitive trauma care to the city of Pietermaritzburg and the surrounding catchment 
area with a total population of about three million people. Penetrating trauma represents over $50 \%$ of the workload at our centre. The PMTS is the largest academic trauma service in western KwaZulu-Natal (KZN) province and supports a major teaching load for the University of KwaZulu-Natal. It is responsible for undergraduate, postgraduate, and subspecialist fellowship training for trauma surgery for both local and international doctors. It is headed by a full professor of surgery with four other full-time subspecialty fellowship trained attendings.

\section{The study}

The HEMR was reviewed for the period January 2013 December 2018, and all patients with knife-related assault were identified. Basic demographic data was reviewed. All relevant data pertaining to admission, clinical course, operative intervention and outcome were reviewed.

\section{Results}

During the six-year study period, a total of 9833 trauma patients were admitted to our unit and 2117 patients suffered a knife-related assault. There were 1936 (91.5\%) males and 181 females. The median age was $28(23-34)$ years. The rural/urban split was $846 / 1250$ (unknown: 21 ). There were 819 (39\%) patients with multiple stab wounds. There were 445 head injuries, 572 neck injuries, 258 facial wounds, 939 chest wounds, 649 abdominal wounds, 49 pelvic/urogenital wounds, and 418 upper limb and 105 lower limb wounds. The median ISS was 9 (4-10). The mean heart rate was 88.5 beats per minute $(0-213)$, the mean respiratory rate was $18.1(0-52)$ breaths per minute, the mean systolic blood pressure was $122.0(0-210) \mathrm{mmHg}$ and the mean MAP was $89.2(0-157) \mathrm{mmHg}$.

\section{Radiology}

A total of 1242 chest X-rays, 315 abdominal X-rays and 162 abdominal ultrasounds/FAST were performed. There were 929 CT scans of which there were 634 CT angiograms. A total of 190 contrast studies were performed. The annual breakdown of CT scans is shown in Figure 1.

\section{Operations}

A total of $783(37 \%)$ patients required an operation. These included 9 craniotomy, 447 laparotomy/laparoscopy, 76 thoracotomy/thoracoscopy, 19 median sternotomy, 9 subxiphoid window, 31 neck exploration, 101 vascular exploration and repair, 20 orthopaedic procedure, 22 wound debridement, 3 incision and drainage, and 72 miscellaneous. The rate of laparotomy/laparoscopy was 447/649 (69\%) and of thoracotomy/sternotomy/thoracoscopy 95/939 (10\%). The rate of vascular exploration for upper and lower limb vascular injury was $101 / 523(19 \%)$. Table I shows the absolute number of each procedure each year.

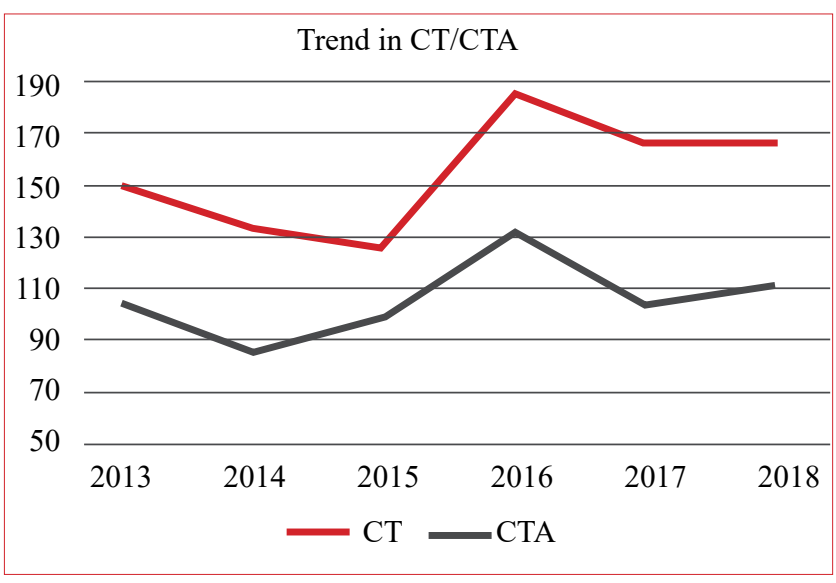

Figure 1: The annual breakdown of CT scans

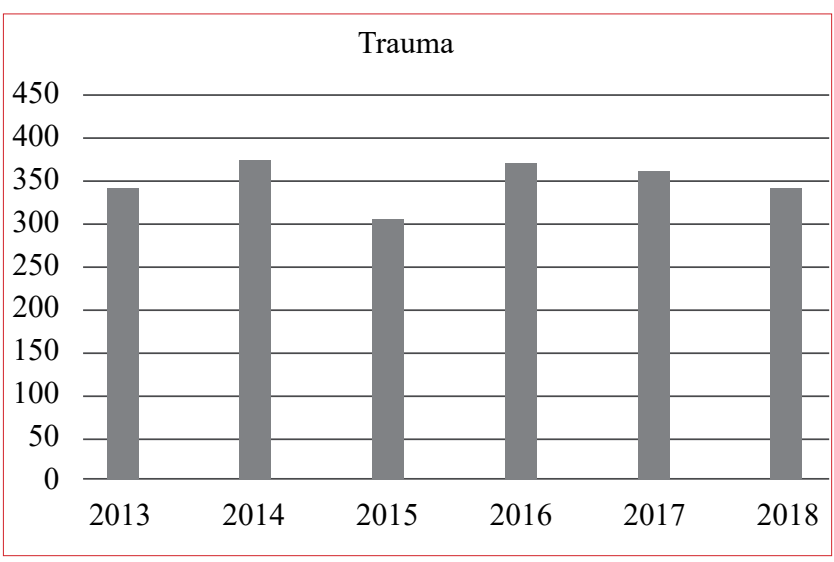

Figure 2: Absolute number of stab victims per year

\section{Outcome}

Overall survival was $2068(97.7 \%)$ and mortality was $49(2.3 \%)$. A total of $162(8.5 \%)$ patients required ICU admission. The median ICU length of stay was $3(1-5)$ days and the median length of hospital stay was $2(0-5)$ days.

\section{Trend analysis}

Figure 2 shows the absolute number of stab wounds managed at our institution per year. Figure 3 shows the rate per month over the six-year period. The absolute number of laparotomies and the rate of laparotomy have remained constant over the time period under review (Figure 4, 5).

\section{Discussion}

Knife crime and assault remains a major problem in South Africa. Our rates appear to be consistent over the half decade under review and the HEMR has allowed us to plot the temporal trends in knife-related assault in the city of Pietermaritzburg. This suggests that the HEMR is a reliable tool and is capturing data appropriately. ${ }^{10,12}$ As HEMR

\section{Table I: The absolute number of each procedure each year}

\begin{tabular}{lcccccccc}
\hline Operation & $\mathbf{2 0 1 3}$ & $\mathbf{2 0 1 4}$ & $\mathbf{2 0 1 5}$ & $\mathbf{2 0 1 6}$ & $\mathbf{2 0 1 7}$ & $\mathbf{2 0 1 8}$ & Total \\
\hline Laparotomy/Laparoscopy & 78 & 92 & 67 & 68 & 77 & 65 & 447 \\
Thoracotomy/Sternotomy/Thoracoscopy & 10 & 19 & 26 & 21 & 7 & 12 & 95 \\
Neck exploration & 6 & 6 & 3 & 6 & 6 & 4 & 31 \\
Vascular exploration & 23 & 23 & 20 & 12 & 11 & 10 & 100 \\
Craniotomy & 0 & 2 & 0 & 3 & 1 & 3 & 9
\end{tabular}




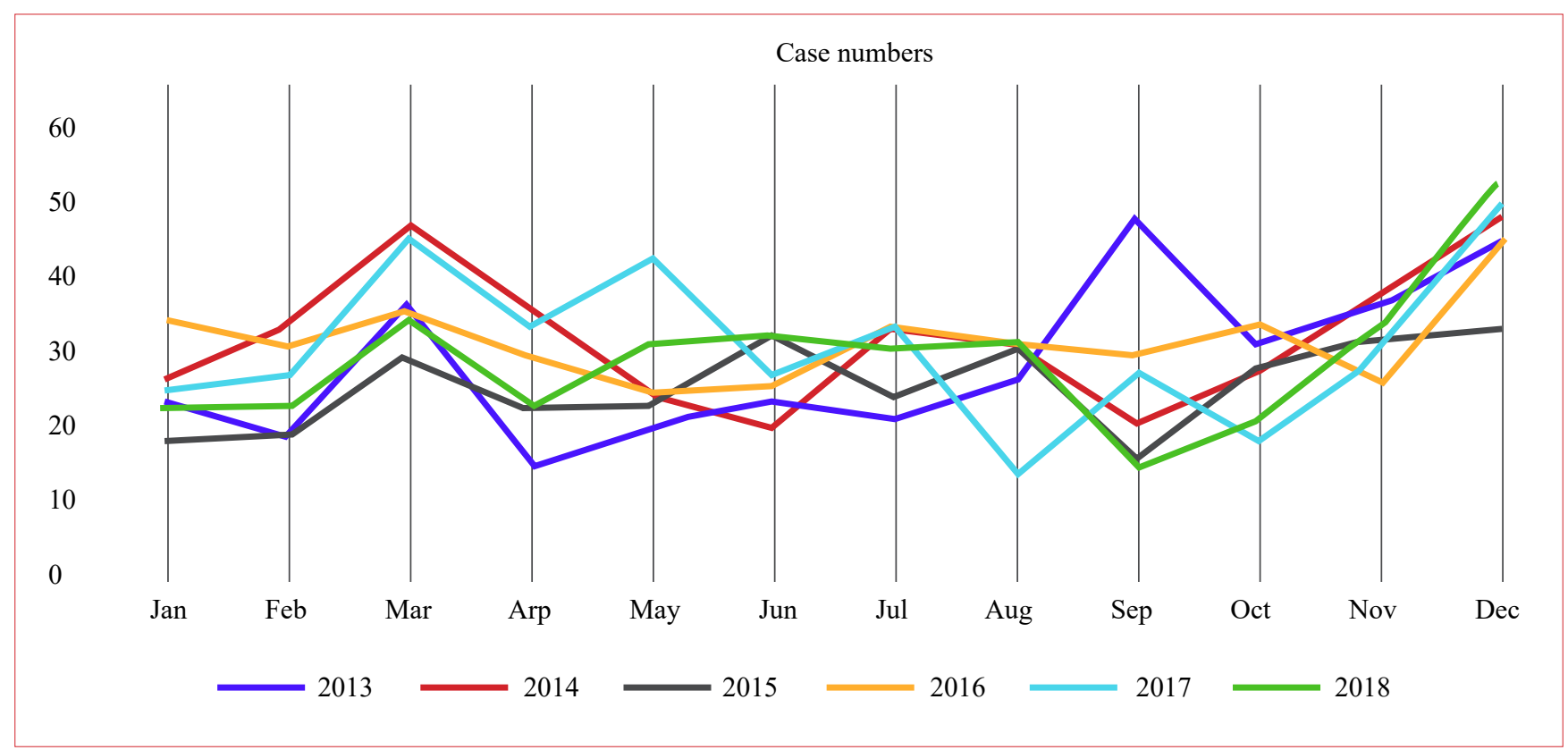

Figure 3: Trends per month over the six-year period

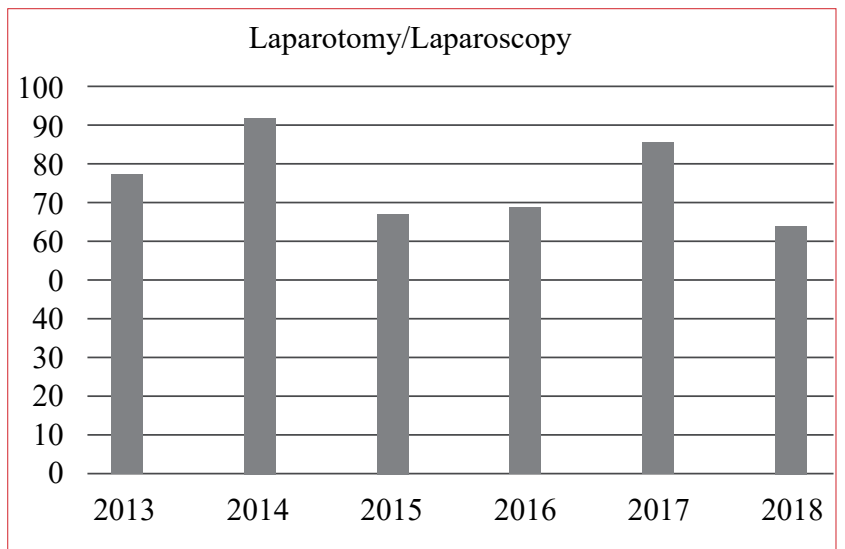

Figure 4: The absolute number of laparotomies

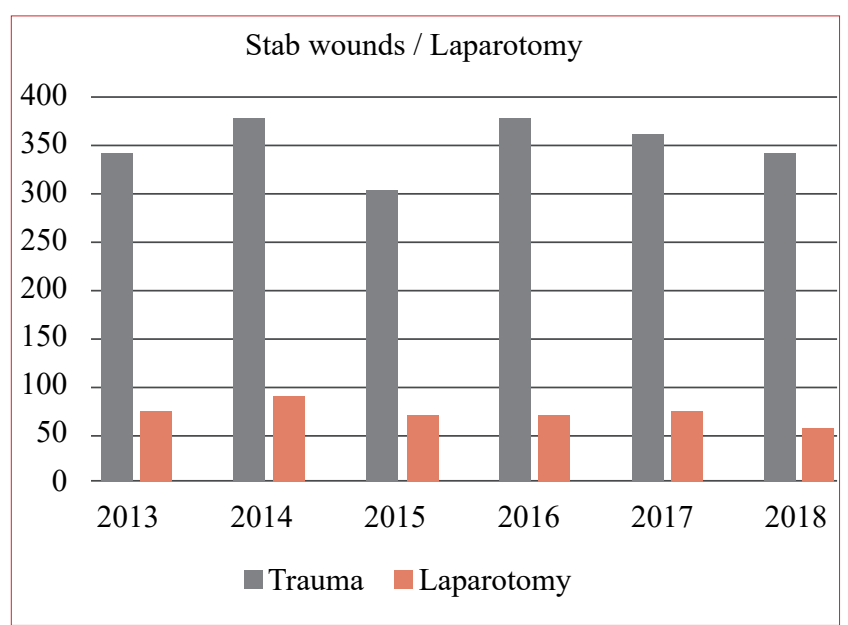

Figure 5: Absolute number of stab wounds compared to laparotomy per year

continues, it is hoped that it will be able to continue to generate accurate and useful data.

The spectrum of injuries related to assault with a knife is diverse with the head and neck, the chest and the abdomen being the body regions most frequently injured. The upper body is most at risk of being injured during a knife-related assault as the assailant is usually standing up and strikes downwards towards the upper body. The range of structures at risk is great and includes the airway and major vascular structures of the neck and upper limbs as well as the chest, mediastinum and the abdomen. Surgeons working in this environment must have sufficient training to be able to manage this wide spectrum of injury.

Focused assessment with sonography for trauma (FAST) has found most application in the assessment of blunt abdominal trauma. Its use in penetrating trauma is evolving and we do make use of it in particular clinical scenarios in parallel with overseas experience. ${ }^{13}$ Although some authors have advocated its use in the assessment of penetrating abdominal trauma, ${ }^{14}$ we have not found a major role for it in that scenario. Our management algorithms for the management of the stab wound to the abdomen remain very clinical. The mere presence of free intra-abdominal fluid post abdominal stab wound does not mandate laparotomy and we therefore do not find much role for FAST in the assessment of abdominal stab wounds. FAST for the assessment of penetrating thoracic trauma, on the other hand, is increasingly used to exclude pericardial fluid collections as well as intrapleural collections of air and fluid. There is also an increasing body of the literature describing the use of computed tomography (CT) scan to assess stab wounds of the abdomen in stable patients. These authors advocate criteria such as wound track trajectory, free intra-peritoneal fluid or air, soft tissue stranding, and bowel wall thickening as important in allowing trauma surgeons to make decisions as to whether the patients can be managed non-operatively. ${ }^{15}$ In our setting, we do not use CT scan to assess stab wounds of the abdomen and restrict our use of this modality to exclude vascular injuries.

Over one third of patients who suffer a stab wound require surgery. The rate of operation for knife wounds to the abdomen is in the order of 69 per cent. Using this clinical approach, our negative laparotomy rate is low and is comparable with other centres who make use of advanced imaging to assist with clinical decision making in this scenario. ${ }^{15,16}$ The rate of operation for stab wounds of the thorax is in the order of ten per cent and the rate of operation for stab wounds of the upper or lower limb is in the order of 19 per cent. The indication here is usually a peripheral 
vascular injury. The absolute numbers of each operation as well as the rates appear to be consistent over the sixyear period under review and this suggests that the HEMR data is accurate. The overall survival rate for knife-related assault is in the order of 97 per cent but there is a significant requirement for ICU and a long duration of hospital stay.

The absolute number of injuries as well as the operative rate have remained constant over the last half a decade. This suggests a consistent population and a consistent rate of trauma. It does not appear as if the burden is increasing, however there is no discernible sign that it is decreasing. This suggests very much a neglected epidemic in our environment. The monthly rates reflect public holidays with marked increases around the April/May period which usually corresponds to the Easter holidays and a period of a number of important public holidays in the country, and a marked increase over December/January which is high summer and reflects the period of the Christmas and New Year holidays. Public holidays appear to be major risk factors for an increase in knife-related assault.

The overall mortality rate for knife crime is low. This means that knife-related mortality is not sufficient or a useful way to track the burden of disease. Great media attention has often been focused on knife-related deaths in cities such as London. ${ }^{2}$ However, knife-related mortality is low and using homicide statistics alone will result in a major under-estimation of the burden of knife-related crime and violence. ${ }^{17}$

\section{Conclusion}

The HEMR has allowed us to plot the temporal trends in knife related assault in the city of Pietermaritzburg which appear to be consistent with no sign of improvement. This suggests a familiarity with treating the knife-related trauma, but a complete failure to develop any preventative strategies to try and reduce this disease.

\section{Conflict of interest}

The authors do not have any relevant disclosures or conflicts of interest for this work.

\section{Funding source}

No funding was utilised for this work.

\section{Ethical approval}

Ethical approval for the maintenance of our registry and for this study was formally approved by the Biomedical Research Ethics Committee of the University of KwaZuluNatal (Reference number: BCA 207/09 and BCA 221/13).

\section{ORCID}

H Uchino (iD https://orcid.org/0000-0002-2898-2857

VY Kong (iD https://orcid.org/0000-0003-2291-2572

A Pantelides (iD https://orcid.org/0000-0001-5232-8452

J Anderson (iD https://orcid.org/0000-0001-8821-2822

H O'Neill (D) https://orcid.org/0000-0003-0414-0011

JL Bruce (iD https://orcid.org/0000-0001-8666-4104

GL Laing (i) https://orcid.org/0000-0001-8075-0386

DL Clarke (i) https://orcid.org/0000-0002-6954-153X

\section{REFERENCES}

1. Moodley NB, Aldous C, Clarke DL. An audit of traumarelated mortality in a provincial capital in South Africa. S Afr J Surg. 2014 Nov;52(4):101-4. PubMed PMID:28876698.
2. Al Jazeera News [Internet]. British government vows to tackle 'scourge' of deadly knife crime. 2019 [cited 2019 Mar 7] Available from: http://www.aljazeera.com/news/2019/03/ british-government-vows-tackle-scourge-deadly-knifecrime-190306151752208.html

3. Thornton J. Doctors could be obliged to report youths at risk of knife crime, says home secretary. BMJ. 2019 Apr 1;365:11520. PubMed PMID: 30936066.

4. Timmis S. Doctors should not be legally obliged to report youths at risk of knife crime. BMJ. 2019 May 8;365:I1973. PubMed PMID: 31068321.

5. Hurley R. BMA calls for knife crime to be tackled as a public health concern. BMJ. 2019 Jun 26;365:14424. PubMed PMID: 31243016 .

6. Tribe HC, Harris A, Kneebone R. Life on a knife edge: using simulation to engage young people in issues surrounding knife crime. Adv Simul (Lond). 2018 Oct 4;3:20. PubMed PMID: 30305938.

7. Hern E, Glazebrook W, Beckett M. Reducing knife crime. BMJ. 2005 May 28;330(7502):1221-2. PubMed PMID:15920107.

8. GOV.UK [Internet] Home Office launched anti-knife crime campaign. (Published 2018 Mar 23 from Home Office and Victoria Atkins MP). Available from: http://www.gov.uk/ government/news/home-office-launches-anti-knife-crimecampaign

9. Beinart S, Anderson B, Lee S, Utting D. Youth at risk? A national survey of risk factors, protective factors and problem behaviour among young people in England, Scotland and Wales. In: Communities that Care: London; 2002. p. 56.

10. Laing GL, Bruce JL, Aldous C, Clarke DL. The design, construction and implementation of a computerized trauma registry in a developing South African metropolitan trauma service. Injury. 2014 Jan;45(1):3-8. PubMed PMID: 23827395.

11. Clarke DL. Trauma quality improvement: The Pietermaritzburg Metropolitan Trauma Service experience with the development of a comprehensive structure to facilitate quality improvement in rural trauma and acute care in KwaZulu-Natal, South Africa. S Afr Med J. 2015 Jan 3;105(2):92-5. PubMed PMID: 26242522.

12. Donovan MM, Kong VY, Bruce JL, Laing GL, Bekker W, Clarke DL, et al. The hybrid electronic medical registry allows benchmarking of quality of trauma care: a five-year temporal overview of the trauma burden at a major trauma centre in South Africa. World J Surg. 2019 Apr;43(4):101421. PubMed PMID: 30564923.

13. Gleeson T, Blehar D. Point-of-care ultrasound in trauma. Semin ultrasound CT MR. 2018 Aug;39(4):374-83. PubMed PMID: 30070230.

14. Quinn AC, Sinert R. What is the utility of the focused assessment with sonography in trauma (FAST) exam in penetrating torso trauma? Injury. 2011 May; 42(5):482-7. PubMed PMID: 20701908.

15. Ramirez RM, Cureton EL, Ereso AQ, Kwan RO, Dozier KC, Sadjadi J, et al. Single-contrast computed tomography for the triage of patients with penetrating torso trauma. J Trauma. 2009 Sep; 67(3):583-8. PubMed PMID: 19741404.

16. Van Waes OJF, Van Lieshout EMM, Van Silfhout DJ, Halm JA, Wijfels MME, Verhofstad MHJ, et al. Selective non-operative management for penetrating abdominal injury in a Dutch trauma centre. Ann R Coll Surg Engl. 2020 May;102(5):37582. PubMed PMID: 32233854.

17. Office for National Statistics [Internet] Homicide in England and Wales: Year ending March 2018. (Released 2019 Feb 7). Available from: https:/www.ons.gov.uk/peoplepopulation andcommunity/crimeandjustice/articles/homicideinengland andwales/yearendingmarch2018 